\title{
Cosmogenic nuclide burial dating of Liuwan Paleolithic site in the Luonan Basin, Central China
}

\author{
WANG Kexin ${ }^{1}$, XU Xinghua ${ }^{1}$, 'SUN Xuefeng ${ }^{1}$, TU Hua ${ }^{2}$, ZENG Qiongxuan"1, \\ LU Yiming ${ }^{1}$, LU Huayu ${ }^{1}$, WANG Shejiang ${ }^{3,4}$ \\ 1. School of Geography and Ocean Science, Nanjing University, Nanjing 210023, China; \\ 2. BGEG, School of Earth Sciences, China University of Geosciences, Wuhan 430074, China; \\ 3. Key Laboratory of Vertebrate Evolution and Human Origins of Chinese Academy of Sciences, Institute of \\ Vertebrate Paleontology and Paleoanthropology, CAS, Beijing 100044, China; \\ 4. CAS Center for Excellence in Life and Paleoenvironment, Beijing 100044, China
}

\begin{abstract}
The Luonan Basin is a key region of early human settlement in Central China with more than 300 discovered Paleolithic sites. Artifact layer 1 of the Liuwan site was dated to approximately 0.6 million years (Ma) based on correlation with the well-dated loess-paleosol sequence of the central Chinese Loess Plateau. This study reassessed the age of the Liuwan artifact layer via an absolute dating method, namely, ${ }^{26} \mathrm{Al} /{ }^{10} \mathrm{Be}$ burial dating. We determined the burial age of artifact layer 1 , which was most likely at least $0.60 \pm 0.12 \mathrm{Ma}\left(10^{\prime}\right)$, using three simple burial ages. The new burial age confirmed the previous estimated age and provided a considerably accurate age range. Therefore, we suggest the use of the ${ }^{26} \mathrm{Al} /{ }^{10} \mathrm{Be}$ burial dating method in thin loess-covered Paleolithic sites around the Qinling Mountain Range is helpful to understand the early human behavior.
\end{abstract}

Keywords: Luonan Basin; loess; Paleolithic artifact; Middle Pleistocene; Cosmogenic nuclides

\section{Introduction}

China is a key area of early human settlement in East Asia during the Pleistocene. The Qinling Mountain Range (QMR) in Central China is a recognized center of early human occupation (Woo, 1964, 1966; Xue, 1987; Li and Etler, 1992; Wang et al., 1997, 2004, 2005, 2008; SPIA et al., 2007, 2008; Lu et al., 2007, 2011a, 2012, 2017; Wang and Lu, 2014, 2016; Sun et al., 2017), which can correspond to the well-known Nihewan Basin in North China (Chia and Wei, 1978; Zhu et al., 2001; Deng et al., 2006). The QMR is highlighted by hundreds of Paleolithic open-air sites and characteristic artifacts, such as hand axes, spheroids, picks, and heavy-duty scrapers (Wang et al., 2005; SPIA et al., 2007).

A few Paleolithic sites in the QMR, such as Liuwan (Lu et al., 2007, 2011b; Sun et al.,

Received: 2018-01-13 Accepted: 2018-05-30

Foundation: National Natural Science Foundation of China, No.41572155, No.41690111; The Global Change Program of the Ministry of Science and Technology of China, No.2016YFA0600503

Author: Wang Kexing, PhD, specialized in cosmogenic nuclide burial dating.

"Corresponding author: Sun Xuefeng, Associate Professor, E-mail: xuefeng@nju.edu.cn 
2014), Qijaojiayao (Lu et al., 2007, 2011a), Yaochangwan (Sun et al., 2012; Wang et al., 2014), and Luojiacun (Sun et al., 2017), have been dated approximately 0.60 Ma. The period of dense hominin settlement in the QMR was approximately 0.60 Ma. However, only several hominin fossil sites were found during this period (approximately $0.50-0.80 \mathrm{Ma}$ ) in China based on credible archaeological data. These archaeological sites were distributed between $20^{\circ} \mathrm{N}$ and $40^{\circ} \mathrm{N}$ latitude (Figure 1). Therefore, hominin settlement and distribution in the QMR during approximately $0.60 \mathrm{Ma}$ are important for understanding early human evolution in China.

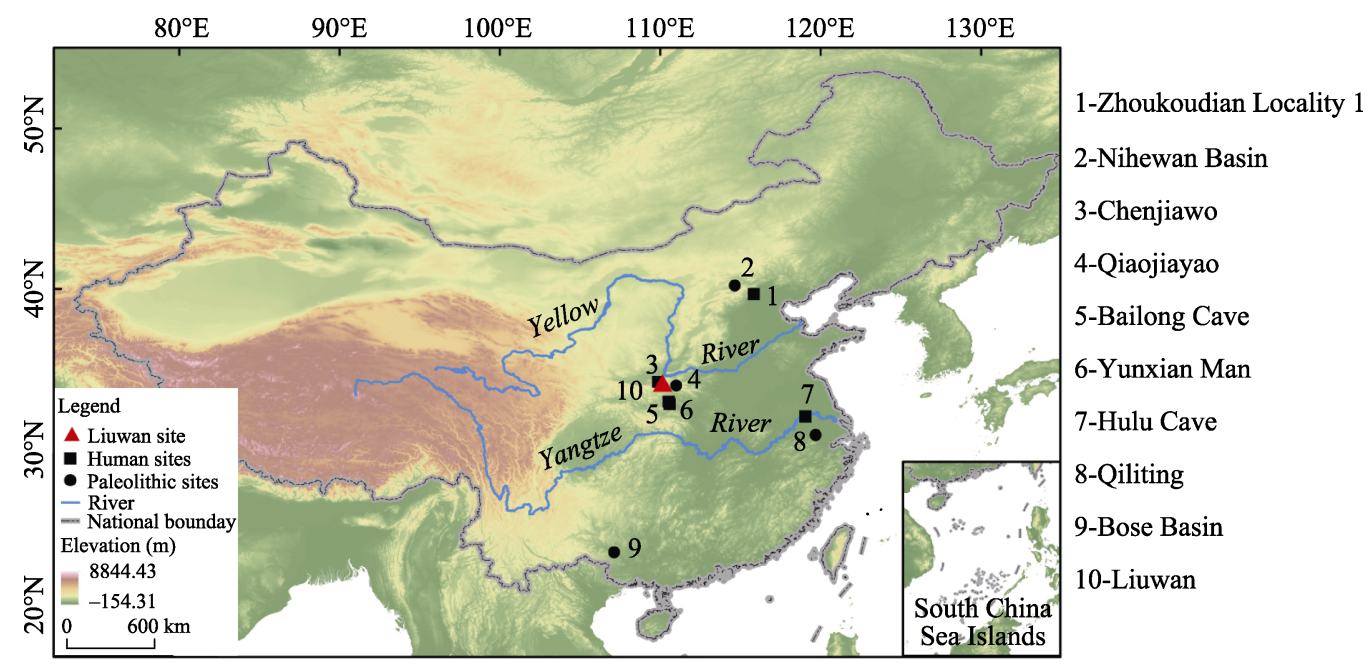

Figure 1 Locations of the Liuwan Paleolithic site in China and other Middle Pleistocene (approximately 0.50-0.80 Ma) hominin fossil and Paleolithic sites

An old and deeply rooted question is whether climate change shapes human evolution (Potts, 1998, 2012). Landforms and elevation are two important influential factors in human evolution. Hominin settlements were mainly located in riverine areas or fluvial terraces, particularly in medium-sized fluvial basins in China (Lu et al., 2017), such as the Nihewan Basin (Zhu et al., 2001, 2007) and the Bose Basin (Hou et al., 2000). Many Middle Pleistocene hominin fossil and Paleolithic sites, such as Zhoukoudian Locality 1 (Shen et al., 2009), Chenjiawo (An and Ho, 1989), and Yunxian Man (Li and Etler, 1992; Chen et al., 1997), are on the second step or the transition between the second and third steps in China (Lu et al., 2017) (Figure 1). Although Hulu Cave (Zhao et al., 2001; Liu et al., 2005) and Qiliting (Archaeology and Office, 2009) are in the Middle-Low Yangtze Plains, these areas are in hilly and mountainous locations near rivers (Figure 2).

The QMR in Central China is a natural barrier that functions as a boundary between the southern and northern climatic regimes and is a sensitive area for climate change controlled by the Asian monsoon. The QMR is a representative zone for the middle latitude, intermountain basins, and warm areas. Thus, Paleolithic discoveries are found in the Luonan and Lushi Basins along the South Luohe River Valley in eastern QMR, in the Hanzhong, Ankang, Yunxian, and Danjiang basins along the Hanjiang River Valley in southern QMR, and in the Lantian Basin along the Bahe River Valley in northern QMR (Figure 2). All these Paleolithic sites are covered with thin loess deposits along medium-sized rivers. 


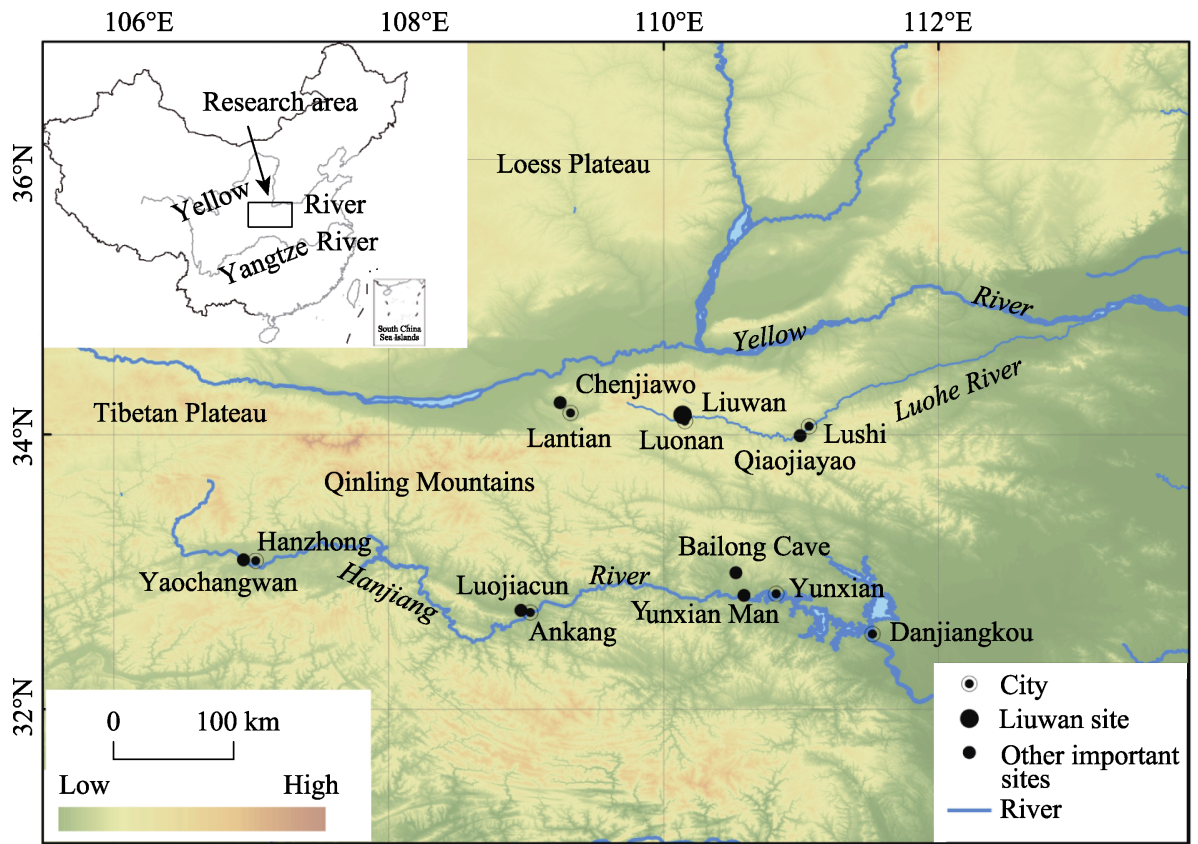

Figure 2 Location of the Liuwan Paleolithic site in the Luonan Basin and other Paleolithic sites approximately $0.60 \mathrm{Ma}$ in the Qinling Mountains Range

We dated many Paleolithic sites (Lu et al., 2007, 2011a, 2011b; Sun et al., 2012, 2014, 2016, 2017) in the QMR using pedostratigraphic correlation with the well-dated loess-paleosol sequence of the Luochuan loess section of the central Chinese Loess Plateau (CLP). We identified a certain range of age error in these Paleolithic sites due to restrictions imposed by the paleomagnetic dating method and the problematic magnetic susceptibility used in thin and atypical loess deposition areas.

An absolute age control from a radioisotopic dating method is required to assess previously established chronologies of these Paleolithic sites. In the current study, we attempted to date the Liuwan Paleolithic site in the Lunan Basin by using the ${ }^{26} \mathrm{Al} /{ }^{10} \mathrm{Be}$ burial dating method. This method is a relatively new radioisotopic dating technique based on the built-up and radioactive decay of two cosmogenic nuclides.

\section{Geographical, archaeological, and stratigraphic settings}

\subsection{Geographical setting}

The Luonan Basin is an intermountain depression in the upper drainage of the South Luohe River (Figure 2). The terrace system of this river is composed of alluvial and thin loess deposits along the flanks of the river valleys. The Liuwan Paleolithic site $\left(34^{\circ} 08^{\prime} 37^{\prime \prime} \mathrm{N}\right.$, $110^{\circ} 08^{\prime} 13^{\prime \prime} \mathrm{E}$; $948 \mathrm{~m}$ above sea level) is located $6 \mathrm{~km}$ north of Luonan City. This site is situated on the second terrace of the Maping River, which is the main tributary of the South Luohe River (Figure 2). Low hills with an average elevation of $1000 \mathrm{~m}$ are found along both sides of the Maping River. This river is short, and the Liuwan site is only approximately 10 $\mathrm{km}$ from its headstream. 


\subsection{Archaeological setting}

More than 20,000 lithic artifacts in over 300 Paleolithic sites have been discovered in the Luonan Basin from low to high terraces along the South Luohe River, thereby making the latter the richest Paleolithic artifact basin in Central China (Wang et al., 2005; SPIA et al., 2007).

The Luonan Basin was first determined to be attractive to the prehistoric community in the 1990s after a few Paleolithic artifacts were individually collected on the surface (by SJ Wang) from various landforms in this region. Thereafter, several sites with in situ artifacts, including Liuwan (locality 1), which is the most representative and contains distinct alternations of loess and paleosol, have been excavated and studied (Lu et al., 2007, 2011a, 2011b). In 2009, Sun et al. (2014) revisited the site and found two additional localities (localities 2 and 3) (Figure 3). Two in situ stone artifact layers were identified and more than 200 artifacts, including stone hammers, scrapers, points, cores, flakes, debris, and chunks, were unearthed during the trial excavation.

The loess deposit is approximately $500 \mathrm{~cm}$ thick in Liuwan locality 3, and three loess units interleaved with four paleosol complexes were identified (Figure 3). Artifact layer 1 lies approximately $160 \mathrm{~cm}$ below layer 2 . This artifact layer is between $445 \mathrm{~cm}$ and $450 \mathrm{~cm}$ deep and contains 33 artifacts. Artifact layer 2 is situated at $305 \mathrm{~cm}$ and has a thickness of 5 $\mathrm{cm}$. A total of 107 artifacts were excavated in this locality.

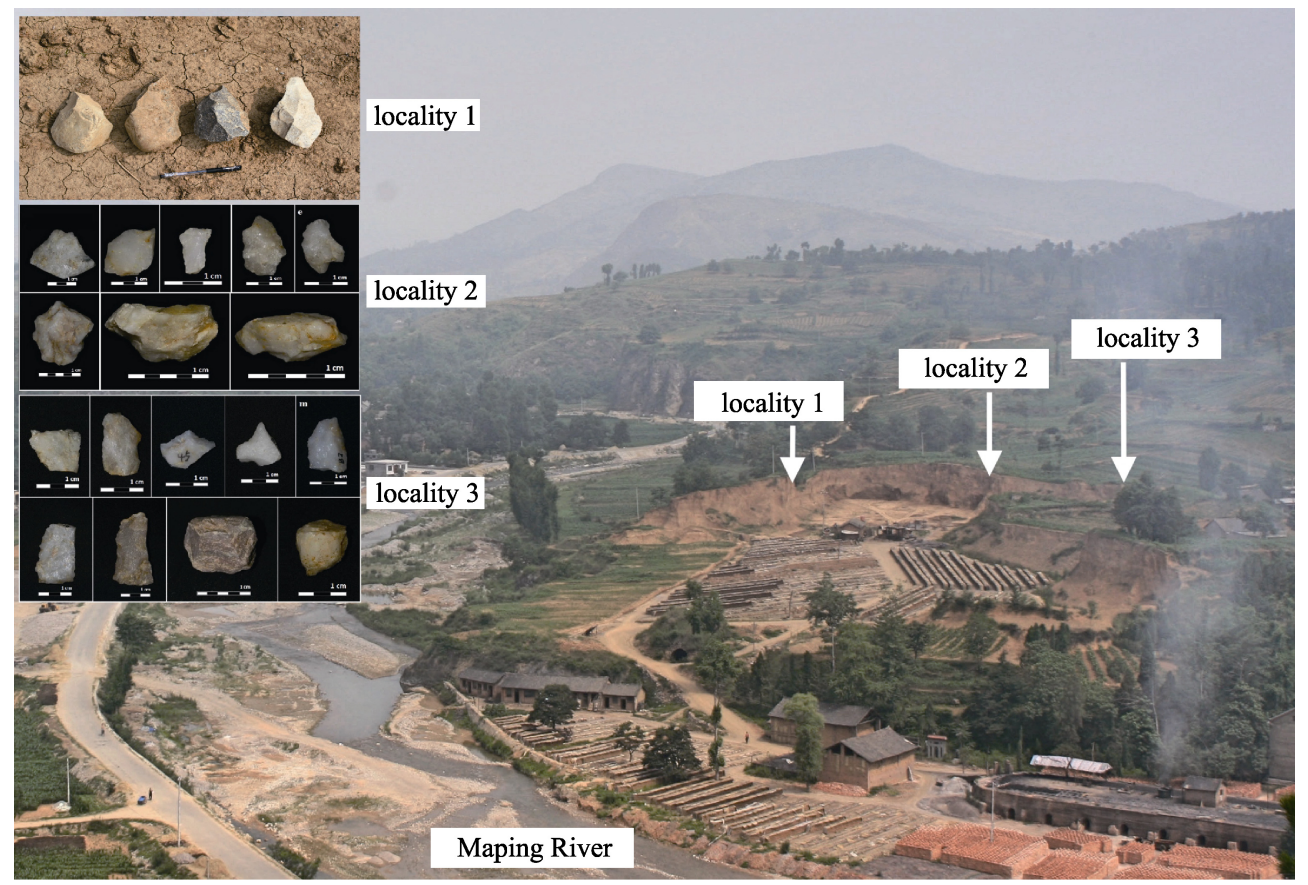

Figure 3 Positions and Paleolithic artifacts of localities 1, 2, and 3 in the Liuwan site. Collected hand axes in locality 1, excavated Paleolithic artifacts in artifact layer 1 in locality 2, and excavated Paleolithic artifacts in artifact layer 2 in locality 3 (Lu et al., 2007; Sun et al., 2014).

\subsection{Stratigraphic setting}

We studied the pedostratigraphy and magnetic susceptibility of Liuwan localities 2 and 3 (Sun 
et al., 2014) and compared their results with those of locality 1 and a typical loess-paleosol sequence in Luochuan (Lu et al., 2007). The result is still comparable although magnetic susceptibility, as a paleoclimate proxy in the Liuwan site, differs from the magnetic susceptibility recorded in the loess-paleosol sequence of the CLP (Lu et al., 2007; Sun et al., 2014). Nevertheless, we significantly correlated localities 1, 2, and 3 using the L5 layer as a prominent marker in the pedostratigraphy and magnetic susceptibility records (Sun et al., 2014). We found S5, L5, S4, S3, L3, S2, L2, S1, and L1 layers in locality 2. Only S5, L5, and the combined S4 and S3 layers were found in locality 3 for the upper part of the loess deposition transferred by local farmers for brick making. Although the loess deposit is thin, no evident hiatus was generally observed in the section. As shown in Figure 3, the loess-paleosol sequence in the Liuwan section is a condensed and "mini" type of the Luochuan loess-paleosol sequence.

Artifact layer 2 was suggested to be located in paleosol unit S5SS2, whereas artifact layer 1 is located in the S5SS3 soil unit based on the pedostratigraphy and magnetic susceptibility of localities 1, 2, and 3 (Sun et al., 2014). Therefore, the approximate ages of the two layers are 0.60 Ma (Lu et al., 1999).

\section{Method and experiments}

\subsection{Sampling}

We collected three sets of Paleolithic artifacts from artifact layer 1 at the bottom of the Liuwan site for ${ }^{26} \mathrm{Al} /{ }^{10} \mathrm{Be}$ burial dating. This area was the lower artifact layer. Each set of samples comprised four to five pieces of vein quartz chunks (Figure 4). These samples were collected in situ from the loess deposits.

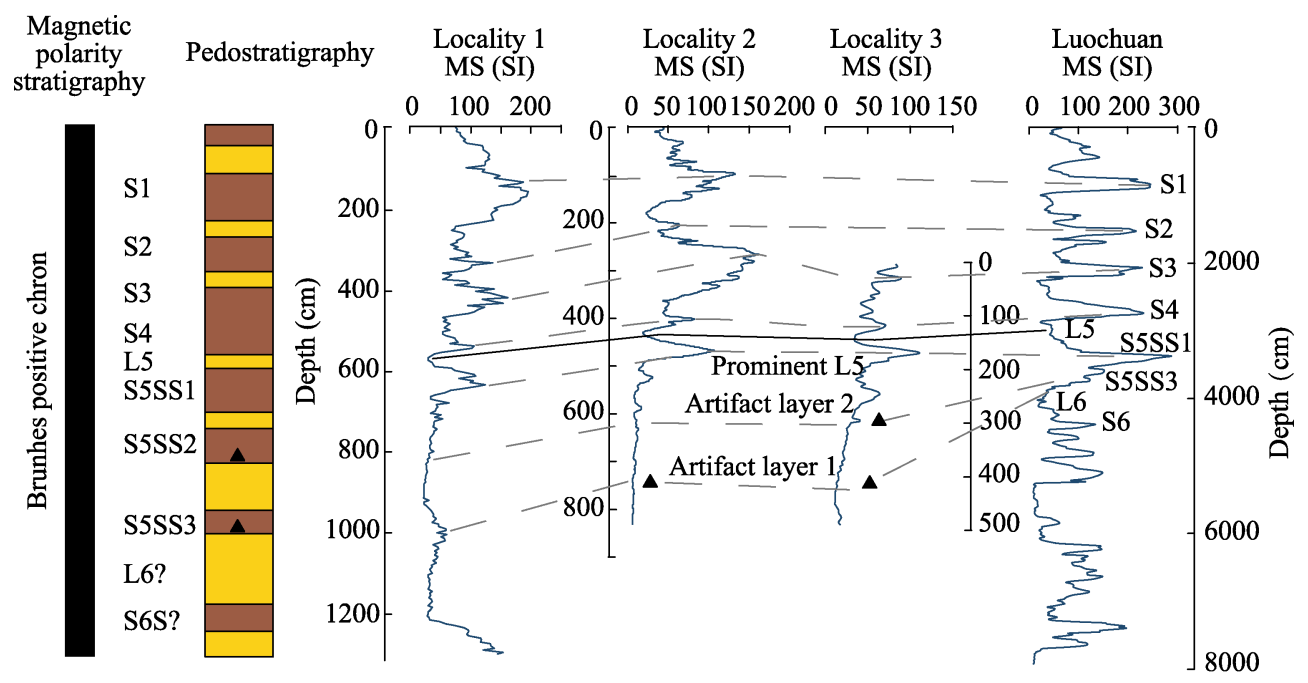

Figure 4 Positions of ${ }^{26} \mathrm{Al}$ and ${ }^{10} \mathrm{Be}$ burial dating samples in artifact layer 1 (black triangles) in the Liuwan localities and magnetostratigraphy, pedostratigraphy, and magnetic susceptibility records correlated with the Luochuan loess-paleosol sequence in Central CLP (Lu et al., 2007; Sun et al., 2014)

\section{$3.2{ }^{26} \mathrm{Al} /{ }^{10} \mathrm{Be}$ burial dating}

The ${ }^{26} \mathrm{Al} /{ }^{10} \mathrm{Be}$ burial dating technique is an important method for dating quartzose deposits 
buried in the past $0.3-5.0 \mathrm{Ma}$ and is particularly used in regions where $\mathrm{K} / \mathrm{Ar}(\mathrm{Ar} / \mathrm{Ar})$ is inapplicable. After its first application to cave deposits (Granger et al., 1997), the ${ }^{26} \mathrm{Al} /{ }^{10} \mathrm{Be}$ burial dating method has been successfully used in river fluvial deposits (Granger and Smith, 2000), lacustrine sediments (Kong et al., 2009), and conglomerate deposits (Kong et al., 2011; Tu et al., 2017).

The basic theory of ${ }^{26} \mathrm{Al} /{ }^{10} \mathrm{Be}$ burial dating has been elucidated by Granger and Muzikar (2001) and Granger (2014). The theory assumes that quartz mineral is gradually exposed in an outcrop that erodes steadily, and certain amounts of ${ }^{26} \mathrm{Al}$ and ${ }^{10} \mathrm{Be}$ will be produced by secondary cosmic rays. The ratio of the production rates of the two nuclides is basically constant and is typically assumed to be 6.8 . If quartz is buried by meters of sediments or rushed into caves, then cosmogenic ${ }^{26} \mathrm{Al}$ and ${ }^{10} \mathrm{Be}$ production drastically decelerates. The inherited nuclides decay according to their specific half-lives, whereas a continued slow accumulation of nuclides through muon-induced reactions may persist. For samples that inherited a high concentration of nuclides and were buried deeply and rapidly, post-burial production is minimal and can be safely disregarded. In this case, the calculated age is referred to as the simple burial age. However, the reliability of simple burial dating will be affected in two cases. In the first case, the sample was not buried rapidly and deeply enough to be shielded quantitatively against cosmic rays; thus, the obtained age result will be underestimated. In the second case, the sample experienced prior burial before the last deposition; thus, the age result will be overestimated.

\subsection{Sample preparation and measurements}

The samples were pretreated in Nanjing University and Nanjing Normal University in China. Raw samples were crushed into submillimeter grains, and samples between $0.2 \mathrm{~mm}$ and 0.5 $\mathrm{mm}$ were sieved out and purified through hydrofluoric acid (HF) leaching and magnetic and gravimetric separations. Then, the samples were analyzed in the Australian Nuclear Science and Technology Organization (ANSTO). The purified quartz (50-100 g) was dissolved in $\mathrm{HF} / \mathrm{HNO}_{3}$ and spiked with approximately $0.3 \mathrm{mg}{ }^{9} \mathrm{Be}$ carrier. After $\mathrm{HF}$ volatilization, Fe was removed by $\mathrm{pH}$-controlled precipitation. $\mathrm{Al}$ and $\mathrm{Be}$ were separated by ion exchange chromatography, and $\mathrm{Be}$ was further purified using precipitation and chromatography. $\mathrm{Al}$ and $\mathrm{Be}$ were then precipitated as hydroxides and transformed into oxides in a furnace at $800^{\circ} \mathrm{C}$. $\mathrm{Al}_{2} \mathrm{O}_{3}$ and $\mathrm{BeO}$ were loaded into cathodes for ${ }^{10} \mathrm{Be} /{ }^{9} \mathrm{Be}$ and ${ }^{26} \mathrm{Al} /{ }^{27} \mathrm{Al}$ measurements using an
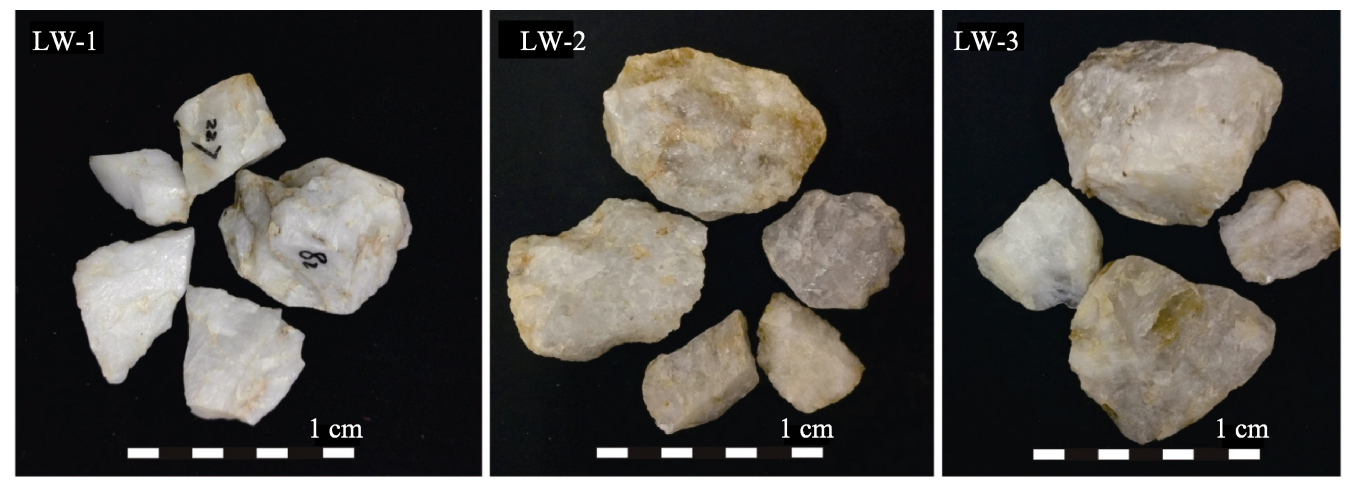

Figure 5 Dating samples from artifact layer 1 in Liuwan locality 3 (each group is a mixture of several vein quartz chunks) 
accelerator mass spectrometer at the ANTARES Accelerator Mass Spectrometry (AMS) Facility, ANSTO.

\section{Result}

The AMS measurement of the three samples from the Liuwan site resulted in relatively good precision, namely, $2 \%-4 \%$ for ${ }^{26} \mathrm{Al} /{ }^{27} \mathrm{Al}$ and approximately $2 \%$ for ${ }^{10} \mathrm{Be} /{ }^{9} \mathrm{Be}$. The integrated precision percentages in nuclide concentration were $5 \%-6 \%$ and approximately $3 \%$ for ${ }^{26} \mathrm{Al}$ and ${ }^{10} \mathrm{Be}$, respectively. Table 1 lists the nuclide concentrations and the corresponding simple burial ages. The simple burial ages (i.e., LW-1: $0.14 \pm 0.11 \mathrm{Ma}$; LW-2: $0.20 \pm 0.13 \mathrm{Ma}$; and LW-3: $0.60 \pm 0.12 \mathrm{Ma}$ ) were calculated by assuming that the samples did not experience prior burial and did not undergo post-burial production.

Table 1 Cosmogenic nuclide concentrations and simple burial ages of the vein quartz chunks from artifact layer 1 in Liuwan locality 3

\begin{tabular}{lccccccc}
\hline Sample & Description & $\begin{array}{c}\text { Burial } \\
\text { depth } \\
(\mathrm{m})\end{array}$ & $\begin{array}{c}{ }^{10} \mathrm{Be} \text { concentra- } \\
\text { tion } \\
\left(\times 10^{6} \mathrm{at} \mathrm{g}^{-1}\right)\end{array}$ & $\begin{array}{c}{ }^{26} \mathrm{Al} \text { concentra- } \\
\text { tion } \\
\left(\times 10^{6} \text { at } \mathrm{g}^{-1}\right)\end{array}$ & ${ }^{26} \mathrm{Al} /{ }^{10} \mathrm{Be}$ & $\begin{array}{c}\text { Minimum age } \\
(\mathrm{Ma})\end{array}$ & $\begin{array}{c}\text { Burial age } \\
(\mathrm{Ma})\end{array}$ \\
\hline LW-1 & Paleolithic artifacts & 4.5 & $0.2314 \pm 0.0062$ & $1.4401 \pm 0.0719$ & $6.223 \pm 0.352$ & $0.144 \pm 0.115$ & $0.144 \pm 0.115$ \\
LW-2 & Paleolithic artifacts & 4.5 & $0.1895 \pm 0.0062$ & $1.1502 \pm 0.0686$ & $6.068 \pm 0.412$ & $0.201 \pm 0.137$ & $0.201 \pm 0.137$ \\
LW-3 & Paleolithic artifacts & 4.5 & $0.4182 \pm 0.0113$ & $2.0541 \pm 0.1106$ & $4.912 \pm 0.296$ & $0.599 \pm 0.122$ & $0.599 \pm 0.122$ \\
\hline
\end{tabular}

Minimum ages are obtained by assuming that the samples are completely shielded from cosmic rays after burial, without considering the nuclides produced during and after the depositional process caused by insufficient shielding against cosmic rays.

The accuracy of the simple burial ages highly depends on the validation of the two assumptions. First, we considered that the Liuwan samples were unlikely to have prior burial history because the Liuwan site is situated on the second terrace of the Maping River, which is approximately $10 \mathrm{~km}$ to the headstream of the river. The artifacts, including our dating samples, were most likely made of raw materials collected from the river bed at the time of human occupation. No depositional basin is present upstream; hence, the possibility that our samples might have been buried previously elsewhere is unlikely. Accordingly, the overestimation of the simple burial ages is improbable.

Second, the dating samples were buried in approximately $4.5 \mathrm{~m}$-thick loess-paleosol. The overburden was insufficiently thick to shield quantitatively against cosmic rays, and the sedimentation rate of these aeolian deposits was relatively slow. Thus, the nuclides produced during and after the sedimentation process could not be completely disregarded. Moreover, the simple burial ages of the samples should have been underestimated. Although the three samples are supposed to be of the same true age and have identical post-burial components, their apparent ages vary significantly. One reason is that the underestimation degree of different samples depends on their inherited nuclide concentrations, i.e., samples with high concentrations yielded old apparent simple burial ages. The Liuwan samples followed this tendency within the error range.

The three simple burial ages are most likely minimal estimates; therefore, we suggest to use the oldest one (LW-3: $0.60 \pm 0.12 \mathrm{Ma}$ ) to mark the minimal age of cultural layer 1 in the Liuwan site. 


\section{Discussion}

\subsection{Dating problems in the QMR}

With loess-paleosol alternations contained loess. Loess is considered a significant archive of past environmental changes and provides a precise time series for studying hominin evolution. However, issues remain despite our successful application of optically stimulated luminescence (OSL) dating, thermally transferred OSL (TT-OSL) dating of quartz, post-infrared infrared stimulated luminescence (post-IRIRSL) dating of K-feldspars, magnetostratigraphic analyses, and pedostratigraphic correlation with the well-dated loess-paleosol sequence of the CLP to set a basic time series for several sites (Sun et al., 2012, 2013, 2016, 2017).

The loess deposited in the southern and eastern Qinling Mountain areas differs from the typical loess deposited in the CLP. Accordingly, the thin loess deposit in a few high terraces is merely a short segment that contains the old part of the entire loess-paleosol sequence, whereas the young part on the surface has been eroded (Guo et al., 2013; Sun et al., 2017). This scenario presents a major obstacle to directly comparing the incomplete loess-paleosol sequence with the typical sequence of the CLP for the missing upper loess-paleosol sequence. In a few sites that are younger than $0.2 \mathrm{Ma}$, the use of the reference OSL, TT-OSL, and post-IRIRSL ages and magnetic susceptibility will enable the correlation of the incomplete loess-paleosol sequence with the complete loess-paleosol sequence in the CLP (Sun et al., 2017).

However, the surface part of the loess section has already exceeded the dating ranges of OSL, TT-OSL, and post-IRIRSL, and no paleomagnetic alternation occurred for the span between approximately $0.20 \mathrm{Ma}$ and $0.78 \mathrm{Ma}$ or older than $0.78 \mathrm{Ma}$. These conditions are considerably common in the Middle to Early Pleistocene Paleolithic sites in the southern and eastern Qinling Mountains, particularly on high terraces. Moreover, suitable materials for the $\mathrm{K} / \mathrm{Ar}$ dating and ${ }^{230} \mathrm{Th} /{ }^{234} \mathrm{U}$ dating in the loess-deposited areas are rarely available. Although we determined a few loess-paleosol segments, no reference age was obtained. The correlation of the incomplete loess-paleosol sequence with the complete loess-paleosol sequence in the CLP is questionable without any radiometric age control.

\subsection{Use of burial dating method}

In this study, the simple burial ages of loess-covered artifacts provided a minimal age control $(0.60 \pm 0.12 \mathrm{Ma})$ for Liuwan locality 3 , thereby allowing the correlation of the incomplete loess-paleosol sequence of the site with the complete loess-paleosol sequence in the CLP and supporting the previous age estimate from Sun et al. (2014). Combined with the normal polarity of the entire strata (Figure 3), which should correspond to the Brunhes Chron $(<0.78 \mathrm{Ma})$, artifact layer 1 in the Liuwan Paleolithic site most likely dates back to 0.60-0.78 Ma. This result reconfirmed that hominins occupied the Luonan Basin since at least $0.60 \mathrm{Ma}$.

Restricted by the unignorable post-burial produced cosmogenic nuclides, a simple burial dating method cannot yield an accurate age for loess-covered samples. Nonetheless, the method can provide a minimal age control to the site, which is valuable in correlating the incomplete paleomagnetic and pedostratigraphic records with the reference ones. 
A simple burial dating method is still recommended only to date samples that were rapidly and deeply buried or loess-covered samples with relatively high inherited nuclides and thick burial depth. For loess-covered samples, an alternative and more reliable approach for dating is the isochron burial dating method (Erlanger et al., 2012). This approach provides a means to determine the true burial age of shallowly buried samples and is proven useful in dating loess-covered samples by analyzing a set of clasts (or stone artifacts) from the same horizon level (Tu et al., 2017).

Many Early-Middle Pleistocene Paleolithic sites in China were recovered from aeolian deposits, such as Xiashu loess, reticulate red clay, and Quaternary red clay. Most of these sites, including the Chenshan Paleolithic sites in Xuancheng, Anhui Province (Yang et al., 1997; Fang et al., 1997), the Qiliting Paleolithic sites in Changin, Zhejiang Province (Xu 2008; Liu et al., 2014), and the Huxushan Paleolithic site in Chishandao, Hunan Province, were dated using the paleomagnetic dating method or stratigraphic correlation. Only a few of these sites have been accurately dated. Therefore, we hope that the application of cosmogenic burial dating can contribute to the chronological framework of Early-Middle Pleistocene human evolution in East Asia.

\section{Conclusions}

Three groups of vein quartz artifacts in artifact layer 1 in Liuwan locality 3 were dated in situ using the simple ${ }^{26} \mathrm{Al}$ and ${ }^{10} \mathrm{Be}$ burial dating method. The simple burial dating ages were $0.14 \pm 0.11,0.20 \pm 0.13$, and $0.60 \pm 0.12 \mathrm{Ma}$. The post-burial production of these samples was not negligible, and the simple burial ages should be considered as minima given the relatively slow sedimentation rate and thin burial depth. Therefore, artifact layer 1 in locality 3 should be older than $0.60 \pm 0.12 \mathrm{Ma}$. The magnetostratigraphical record also indicates that the site is most likely dated to $0.60-0.78 \mathrm{Ma}$. Therefore, the application of the minimum age of the simple ${ }^{26} \mathrm{Al}$ and ${ }^{10} \mathrm{Be}$ burial dating method is useful in dating Paleolithic artifacts in thin loess-covered Paleolithic sites in the QMR and in Southern China.

\section{Acknowledgment}

We thank Prof. David Fink for his help in the laboratory work, and Prof. Guanjun Shen for his help and encouragement.

\section{References}

An Z H, Ho C K, 1989. New magnetostratigraphic dates of Lantian Homo-Erectus. Quaternary Research, 32: 213-221.

Chen T M, Yang Q, Hu Y Q et al., 1997. ESR dating of tooth enamel from Yunxian Homo erectus site, China. Quaternary Science Reviews, 16: 455-458.

Chia L P, Wei C, 1978. A Palaeolithic site at Hsu-Chia-Yao in Yanggao County, Shanxi Province. Acta Archaeologia Sinica, 2: 97-114. (in Chinese)

Deng C L, Wei Q, Zhu R X et al., 2006. Magnetostratigraphic age of the Xiantai Paleolithic site in the Nihewan Basin and implications for early human colonization of Northeast Asia. Earth and Planetary Science Letters, 244: $336-348$.

Erlanger E D, Granger D E, Gibbon R J, 2012. Rock uplift rates in South Africa from isochron burial dating of 
fluvial and marine terraces. Geology, 40: 1019-1022.

Fang Y S, 1997. A Report on Excavation of Chenshan Locality in 1988, Anhui Province. Acta Anthropologica Sinica, 16(2): 96-106. (in Chinese)

Granger D E, 2014. Cosmogenic nuclide burial dating in archaeology and paleo- anthropology. In: Holland H D, Turekian K K (eds.). Treatise on Geochemistry. 2nd ed. Oxford: Elsevier, 81-97.

Granger D E, Kirchner J W, Finkel R C, 1997. Quaternary downcutting rate of the New River, Virginia, measured from differential decay of cosmogenic ${ }^{26} \mathrm{Al}$ and ${ }^{10} \mathrm{Be}$ in cave-deposited alluvium. Geology, 25(2): 107-110.

Granger D E, Muzikar P F, 2001. Dating sediment burial with in situ-produced cosmogenic nuclides: Theory, techniques, and limitations. Earth and Planetary Science Letters, 188(1): 269-281.

Granger D E, Smith L A, 2000. Dating buried sediments using radioactive decay and muogenic production of ${ }^{26} \mathrm{Al}$ and ${ }^{10} \mathrm{Be}$. Nuclear Instruments and Methods in Physics Research Section B: Beam Interactions with Materials and Atoms, 172(1): 822-826.

Guo Y Q, Huang C C, Pang J L et al., 2013. Sedimentological study of the stratigraphy at the site of Homo erectus yunxianensis in the upper Hanjiang River valley, China. Quaternary International, 300: 75-82.

Hou Y M, Potts R, Yuan B Y et al., 2000. Mid-Pleistocene Acheulean-like stone technology of the Bose basin, South China. Science, 287: 1622-1626.

Kong P, Granger D E, Wu F Y et al., 2009. Cosmogenic nuclide burial ages and provenance of the Xigeda paleo-lake: Implications for evolution of the Middle Yangtze River. Earth and Planetary Science Letters, 278 (1/2): 131-141.

Kong P, Zheng Y, Fu B H, 2011. Cosmogenic nuclide burial ages and provenance of Late Cenozoic deposits in the Sichuan Basin: Implications for Early Quaternary glaciations in east Tibet. Quaternary Geochronology, 6(3/4): 304-312.

Li T, Etler D A, 1992. New Middle Pleistocene hominid crania from Yunxian in China. Nature, 357: 404-407

Liu C C, Deng C L, 2014. The effect of weathering on the grain-size distribution of red soils in south-eastern China and its climatic implications. Journal of Asian Earth Sciences, 94: 94-104.

Liu W, Zhang Y, Wu X, 2005. Middle Pleistocene human cranium from Tangshan (Nanjing), Southeast China: A new reconstruction and comparisons with Homo erectus from Eurasia and Africa. American Journal of Physical Anthropology, 127: 253-262.

Lu H Y, Liu X D, Zhang F Q et al., 1999. Astronomical calibration of loess-paleosol deposits at Luochuan, central Chinese Loess Plateau. Palaeogeography, Palaeoclimatology, Palaeoecology, 154: 237-246.

Lu H Y, Sun X F, Wang S J et al., 2011a. Ages for hominin occupation in Lushi Basin, middle of South Luo River, Central China. Journal of Human Evolution, 60(5): 612-617.

Lu H Y, Zhang H Y, Sun X F et al., 2012. Landform, loess deposit and paleoenrivonmental changes in the South Luohe River (Central China) during the Hominin occupations. Quaternary Science, 32: 167-177. (in Chinese)

Lu H Y, Zhang H Y, Wang S J et al., 2007. A preliminary survey on loess deposit in Eastern Qinling Mountains (Central China) and its implication for estimating age of the Pleistocene lithic artifacts. Quaternary Sciences, 27(4): 559-567. (in Chinese)

Lu H Y, Zhang H Y, Wang S J et al., 2011b. Multiphase timing of hominin occupations and the paleoenvironment in Luonan Basin, Central China. Quaternary Research, 76(1): 142-147.

Lu H Y, Zhuo H X, Zhang W C et al., 2017. Earth surface processes and their effects on human behavior in monsoonal China during the Pleistocene-Holocene epochs. Journal of Geographical Sciences, 27(11): 1311-1324.

Potts R, 1998. Variability selection in Hominid evolution. Evolutionary Anthropology, 7: 81-96.

Potts R, 2012. Evolution and environmental change in early human prehistory. Annual Review of Anthropology, 41: $151-167$.

Shaanxi Provincial Institute of Archaeology (SPIA), Cultural Relics Administrative Committee of Shangluo District, Museum of Luonan County, 2007. Huashilang (I): The Paleolithic Open-air Sites in the Luonan Basin. Beijing: Science Press, pp. 1-300. (in Chinese)

Shaanxi Provincial Institute of Archaeology (SPIA), Museum of Luonan County, 2008. Huashilang (II): 
Longyadong Paleolithic Cave Site in the Luonan Basin, China. Beijing: Science Press, pp. 1-272. (in Chinese)

Shen G, Gao X, Gao B et al., 2009. Age of Zhoukoudian Homo erectus determined with ${ }^{26} \mathrm{Al} /{ }^{10} \mathrm{Be}$ burial dating. Nature, 458: 198-200.

Sun X F, Lu H Y, Feng X B et al., 2016. Pedostratigraphy of aeolian deposition near the Yunxian Man site on the Hanjiang River terraces at Yunxian Basin, central China. Quaternary International, 400: 187-194.

Sun X F, Lu H Y, Wang S J et al., 2012. Ages of Liangshan Paleolithic sites in Hanzhong Basin, central China. Quatemary Geochronology, 10(7): 380-386.

Sun X F, Lu H Y, Wang S J et al., 2013. TT-OSL dating of Longyadong Middle Paleolithic site and paleoenvironmental implications for hominin occupation in Luonan Basin (central China). Quaternary Research, 79: $168-174$.

Sun X F, Lu H Y, Wang S J et al., 2014. Age of newly discovered Paleolithic assemblages at Liuwan site Luonan Basin, central China. Quaternary International, 347: 193-199.

Sun X F, Lu H Y, Wang S J et al., 2017. Early human settlements in the southern Qinling Mountains, central China. Quaternary Science Reviews, 164: 168-186.

$\mathrm{Tu}$ H, Shen G J, Granger D et al., 2017. Isochron ${ }^{26} \mathrm{Al} /{ }^{10} \mathrm{Be}$ burial dating of the Lantian hominin site at Gongwangling in northwestern China. Quaternary Geochronology, 41: 174-179.

Wang S J, 2008. A preliminary survey of Paleolithic artifacts and loess deposition in the middle South Luohe River, Eastern Qinling Mountains, central China. Quaternary Sciences, 28: 988-999. (in Chinese)

Wang S J, Lu H Y, Xing L D, 2014. Chronological and typo-technological perspectives on the Palaeolithic archaeology in Lantian, central China. Quaternary International, 347: 183-192.

Wang S J, Shen C, Hu S M et al., 2005. Lithic artefacts collected from open-air sites during 1995-1999 investigations in Luonan Basin, China. Acta Anthropologica Sinica, 24: 87-103. (in Chinese)

Wang S J, Zhang X B, Hu S M, 1997. The significance of paleolithic archaeological work in the Luonan Basin. Chin. Relics Newspaper, 12-07(1). (in Chinese)

Wang S J, Zhang X B, Shen C et al., 2004. A study of lithic assemblages from 1995 excavation at longyadong cave, Luonan basin, China. Acta Anthropologica Sinica, 23: 93-110. (in Chinese)

Wang S J, Zhang X B, Shen C et al., 2014. A study of lithic assemblages from 1995 excavation at Luonan Basin, China. Acta Anthropologica Sinica, 23(2): 93-110. (in Chinese)

Wang X Y, Lu H Y, Zhang W G et al., 2016. Rock magnetic investigation of loess deposits in the Eastern Qingling Mountains (central China) and its implications for the environment of early humans. Geophysical Journal International, 2: 889-900

Woo J K, 1964. Mandible of the Sinanthropus-type discovered at Lantian, Shensi. Vertebrata Palasiatica, 8: 1-12. (in Chinese)

Woo J K, 1966. The hominid skull of Lantian, Shensi. Vertebrata Palasiatica, 10: 1-16. (in Chinese)

Xu X M, 2008. A summary of paleolithic archaeology in Zhejiang Province. Southeast Culture, (2): 6-10. (in Chinese)

Xue X X, 1987. Human fossil tooth from Luonan, Shaanxi, and its geological age. Acta Anthropologica Sinica, 6: 284-288. (in Chinese)

Yang D Y, Li X S, Lu H Y et al., 1997. "Loess" in Xuancheng Prefecture of Anhui Province and Palaeolothic culture. Journal of Geomechanics, 3(4): 85-89. (in Chinese)

Zhao J X, Hu K, Collerson K D et al., 2001. Thermal ionization mass spectrometry U-series dating of a hominid site near Nanjing, China. Geology, 29: 27-30.

Zhejiang Provincial Institute of Cultural Relics and Archaeology, Changxing County Cultural Relics Protection Management Office, 2009. Qiliting and Yindinggang. Beijing: Science Press, 1-266. (in Chinese)

Zhu R X, Deng C X, Pan Y, 2007. Magnetochronology of the fluvio-lacustrine sequences in the Nihewan Basin and its implications for early human colonization of Northeast Asia. Quaternary Sciences, 27: 922-944. (in Chinese)

Zhu R X, Hoffman K A, Potts R et al., 2001. Earliest presence of humans in northeast Asia. Nature, 413: 413-417. 